\title{
XÂY DỰNG BỘ CÔNG CỤ HIỂN THỊ THÔNG TIN DỤ’ BÁO CẢNH BÁO KHÍ TƯợNG THỦY VĂN CHO TINH LONG AN
}

\author{
Nguyễn Quang Ngọc ${ }^{1}$, Nguyễn Hải Sơn ${ }^{2}$
}

Tóm tắt: Hiện nay xu hướng trục quan hóa và bản đồ hóa các thông tin đang được ứng dụng rất hiệu quả trong nhiều ngành, lĩnh vưcc, đặc biệt khí tượng thủy văn. Các phần mềm xủ lý và quản lý các hệ thống thông tin địa lý (GIS) được phát triển mạnh và ngày càng hoàn thiện, cho phép kết nối, chồng chập nhiều lớp, dễ dàng thể hiện các thông tin trên nền bản đồ tự động. Nhằm tận dụng nguồn tài nguyên thông tin GIS có sẵn, chúng tôi đã xây dụng công cu cung cấp thông tin dụ báo thời tiết trên địa bàn tỉnh Long An bằng việc thể kết quả dụ báo trên nền bản đồ GIS. Bài báo này, trình bày nội dung kỹ thuật về xây dưng các module giải mã số liệu dụ báo mô hình số trị GFS của NOAA, module kết nối số liệu dụ báo với truờng thuộc tính GIS và module hiển thị kết quả dụ báo. Kết quả đã tạo được bộ công cu tụ động cung cấp bản tin dụ báo theo bản đồ trục quan đến cấp huyện, xã cho tỉnh Long An, giúp người dùng có thể khai thác sản phẩm qua internet.

Từ khóa: Úng dụng GIS dụ báo thời tiết tỉnh Long An, Dụ báo thời tiết cấp xã tỉnh Long An, Phần mềm Decoding NOAA cho Long An.

Ban Biên tập nhận bài: 08/3/2020 Ngày phản biện xong: 16/4/2020 Ngày đăng bài: 25/04/2020

\section{Mở đầu}

Công nghệ hệ thống thông tin địa lý (GIS) ngày nay đang được ứng dụng rộng rãi trên thế giới trong nhiều lĩnh vực khác nhau, đặc biệt là trong nhiều lĩnh vực có liên quan đến không gian, vị trí địa lý [1]. Đối với lĩnh vực dự báo, cảnh báo khí tượng thủy văn, ngoài cung cấp các các thông tin dự báo bằng trị số thì cần thể hiện các thông tin này trên hình ảnh, bản đồ trực quan để nhiều đối tượng có thể dễ dàng tiếp cận, sử dụng, góp phần nâng cao chất lượng phục vụ xã hội của ngành [2]. Với sự phát triển mạnh mẽ của công nghệ thông tin, đặc biệt là năng lực tính toán, các mô hình dự báo số trị đang ngày càng được ứng dụng phổ biến trong nghiên cứu và dự báo, nhiều sản phẩm từ mô hình dự báo toàn cầu như Global Forecast System (GFS), Global Ensemble Forecast System (GEFS), Climate Forecast System (CFS) của Cơ quan Quản lý đại dương và khí quyển Mỹ NOAA, mô hình Intergrated Forecast

${ }^{\prime} Đ a ̀ i$ Khi tuợng Thủy văn tỉnh Long An ${ }^{2}$ Đài Khí tuợng Thủy văn tỉnh Bình Phwớc

Email: quangngocla@gmail.com, nguyenhaichau6399@gmail.com
Sytem (IFS) của Trung tâm Dự báo hạn vừa châu Âu ECMWF được nhiều quốc gia trên thế giới khai thác và đưa vào sử dụng trong nghiệp vụ dự báo [3]. Tận dụng nguồn tài nguyên thông tin GIS được xây dựng trên địa bàn tỉnh Long An, nghiên cứu đã phân tích và xây dựng công cụ phần mềm giải mã số liệu báo toàn cầu "Decoding NOAA Data”, kết hợp với kinh nghiệm phân tích dự báo của dự báo viên Đài Khí tượng Thủy văn tỉnh Long An kết nối các thông tin này với các hệ thống GIS, lồng ghép và chồng lớp bản đồ về địa hình, các đơn vị hành chính, hệ thông sông, suối và các cơ sở hạ tầng để tạo thành bản đồ dự báo, cảnh báo trực quan đến cấp xã cho tỉnh Long An.

\section{Phương pháp nghiên cứu}

\subsection{Giới thiệu về khu vục nghiên cúu}

Long An là tỉnh nằm trong Vùng Phát triển kinh tế trọng điểm phía Nam (Hình 1), thuộc khu vực đồng bằng sông Cửu Long, với diện tích 449.194,49 ha, Long An có 15 huyện, 192 xã phường và thị trấn.

Nằm trong vùng khí hậu nhiệt đới gió mùa, ẩm, nhiệt độ trung bình hằng tháng $27.2-27.7^{\circ} \mathrm{C}$, nhiệt độ cao nhất vào tháng 4 , thấp nhất vào 
tháng 1. Lượng mưa năm biến động từ $966-1325$ $\mathrm{mm}$. Mùa mưa chiếm trên $70-82 \%$ tổng lượng mưa cả năm, phân bố theo không gian không đều, giảm dần từ khu vực giáp ranh thành phố Hồ Chí Minh xuống phía Tây và Tây Nam. Độ ẩm tương đối trung bình hàng năm là $80-82 \%$. Thời gian chiếu sáng bình quân ngày từ $6,8-7,5$ giờ/ngày và bình quân năm từ $2.500-2.800$ giờ.
Là tỉnh có nền kinh tế nông nghiệp, chủ yếu sản xuất lúa gạo, cây ăn quả và nuôi trồng thủy sản, phụ thuộc rất nhiều vào điều kiện khí tượng thủy văn. Vì vậy, nhu cầu cần chi tiết thông tin dự báo thời tiết, thủy văn phục vụ sản xuất nông nghiệp và phòng, chống thiên tai của tỉnh là rất lớn.

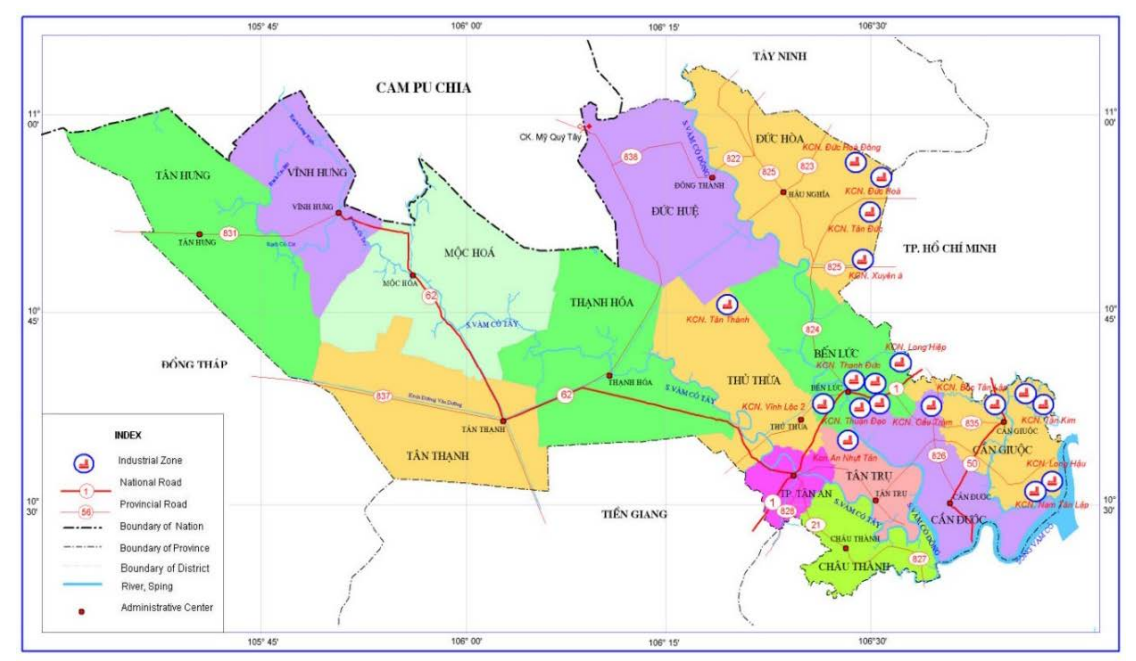

Hình 1. Bản đồ hành chính tỉnh Long An

\subsection{Phương pháp nghiên cúu}

Với mục tiêu tận dụng cơ sở dữ liệu về GIS và cơ sở dữ liệu khí tượng thủy văn đã được xây dựng cho tỉnh, để xây dựng Bộ công cụ cung cấp thông tin dự báo, cảnh báo khí tượng thủy văn chi tiết đến cấp huyện, xã cho tỉnh Long An, nghiên cứu đã sử dụng một số phương pháp sau:

- Sử dụng ngôn ngữ lập trình Visual Studio 2015 để xây dựng công cụ tự động thu nhận và giải mã số liệu dự báo từ mô hình số trị toàn cầu GFS của NOAA và kết nối cơ sở dữ liệu GIS với định dạng ArcInfor, MapInfor.

- Từ kết quả dự báo được kết hợp bởi sản phẩm mô hình NOAA và kinh nghiệm phân tích của dự báo viên được hiển thị chi tiết trên nền bản đồ GIS, nghiên cứu đã xây dựng công cụ webApp bằng ngôn ngữ lập trình PHP (Hypertext Preprocessor) trên hệ điều hành Lilux và nền tảng hỗ trợ công nghệ HTML5, CSS và AJAX để tự động cung cấp bản tin đến cộng đồng, WebApp có thể truy cập trên máy tính cá nhân và thiết bị di động thông minh (Hình 2).

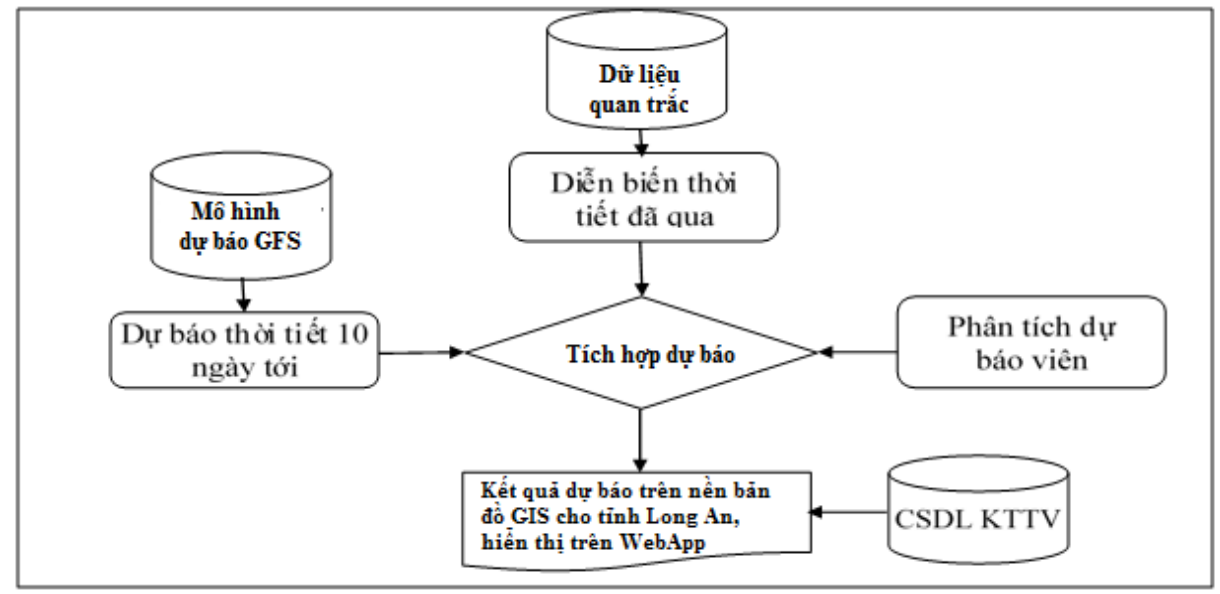

Hình 2. So đồ khối bộ công cu cung cấp thông tin dụ báo cho Long An 


\subsection{Thu thập dĩ liệu}

Để tạo cơ sở dữ liệu GIS hiển thị các loại bản đồ dự báo, nghiên cứu đã thu thập số liệu GIS về hành chính, dân cư, giao thông, thủy lợi từ Sở Tài nguyên và Môi trường tỉnh Long An.

Số liệu dự báo từ mô hình GFS được cập nhật trên website: https://nomads.ncep.noaa.gov. Cơ sở dữ liệu khí tượng thủy văn được sử dụng từ cơ sở dữ liệu của Đài Khí tượng Thủy văn tỉnh Long An.

\section{Kết quả nghiên cứu}

\subsection{Các hoạt động kỹ thuật chính để xây} dụng bộ công cu

GFS (Global Forecast System) là mô hình số trị toàn cầu được phát triển và chạy nghiệp vụ bởi Cục Quản lý đại dương và khí quyển NOAA của Mỹ. Tiền thân của GFS là mô hình AVN (Aviation model). GFS bắt đầu được đưa vào nghiệp vụ dự báo từ năm 1988 tại Trung tâm Khí tượng $(\mathrm{NMC})$ là tiền thân của Trung tâm Dự báo môi trường NCEP. Sau nhiều lần cải tiến, nâng cấp, hiện nay GFS có hạn dự báo tối đa 16 ngày, với 8 ngày đầu có độ phân giải cao và 8 ngày sau có độ phân giải thấp hơn, chạy với tần suất 4 lần/ngày vào các thời điểm $00 \mathrm{Z}, 06 \mathrm{Z}, 12 \mathrm{Z}$ và 18Z, độ phân giải ngang của mô hình ở các mức $1^{\circ}, 0.5^{\circ}$ và $0.25^{\circ}$, độ phân giải thẳng đứng 64 mực, đưa ra sản phẩm ở 4 mực chuẩn 850, 700,
500 và $200 \mathrm{hPa}$ [3]. Sản phẩm dự báo được cung cấp trên website http://nomads.ncep.noaa.gov, để sử dụng hiệu quả sản phẩm này nhằm góp phần nâng cao độ tin cậy của bản tin dự báo, cần phải có bộ công cụ giải mã các tập tin dự báo của GFS, phần mềm tích hợp cơ sở dữ liệu quan trắc tại các trạm khí tượng thủy văn, tích hợp thông tin dự báo trên nền GIS và cung cấp thông tin trên cổng thông tin điện tử của tỉnh Long An. Kết quả xây dựng bộ công cụ dự báo trên nền tảng GIS, từ các hoạt động kỹ thuật đã được nhóm nghiên cứu thực hiện như sau.

3.1.1. Xây dựng công cu giải mã số liệu dụ báo mô hình GFS

Số liệu dự báo của GFS được cung cấp trên website của NOAA dưới định dạng nhị phân GRIB [4]. Để thu thập và sử dụng được nguồn số liệu này, công cụ giải mã được thiết kế gồm các module (mô đun) chính: Module tự động cập nhật số liệu định dạng GRIB2 từ website của NOAA (Hình 3); module giải mã tập tin từ GRIB thành tập tin GRID; module chuyển đổi số liệu dạng lưới trong tệp tin GRID thành dữ liệu số vào cơ sở dữ liệu hành chính cấp huyện, xã trong hệ thống cơ sở dữ liệu GIS; module kết nối trường thuộc tính của GIS với cơ sở dữ liệu dự báo chuyển đổi từ tệp GRID.

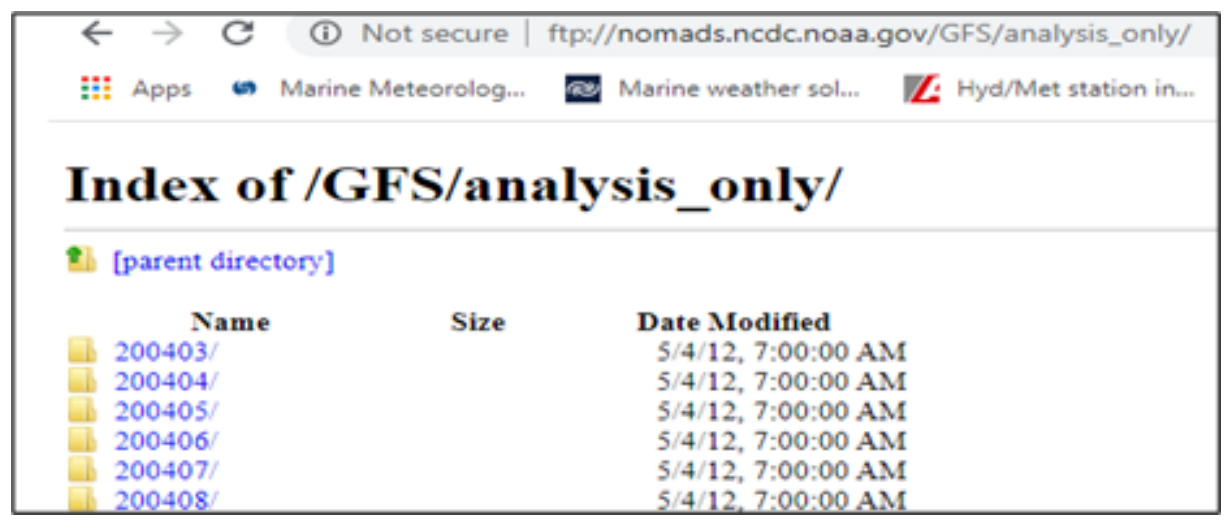

Hình 3. Số liệu dụ báo bằng mô hình GFS được cung cấp trên website của NOAA

Để chuyển đổi từ định dạng GRIB2, công cụ đọc và giải mã số liệu định dạng GRIB được thiết kế tạo ra 02 tập tin được kết xuất gồm: Tập tin Grid.txt lưu trữ thông tin về không gian số liệu thu nhận; tập tin Header.txt lưu trữ các thông tin để có thể truy xuất được trường số liệu cụ thể tại một thời điểm xác định. Cấu trúc tập tin Header được mô tả như Hình 4. 


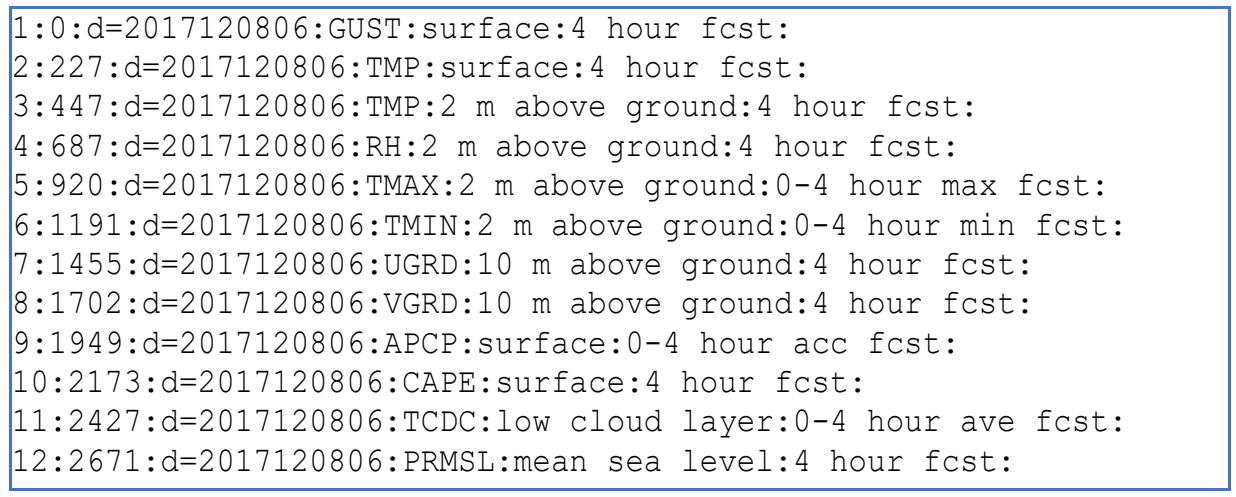

Hình 4. Cấu trúc tập tin Header của định dạng số liệu GRIB2

Hai tập tin trên, sẽ được kết nối với module tiết về các tập tin lưới số liệu với mỗi tập tin chứa đọc, chuyển đổi số liệu các trường yếu tố thời một yếu tố dự báo tại một thời điểm nhất định.

\begin{tabular}{|c|c|c|c|}
\hline$\wedge$ & Date modified & Type & Size \\
\hline 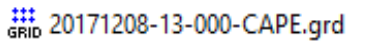 & 08/12/2017 22:36 & Surfer Grid & $1 \mathrm{~KB}$ \\
\hline 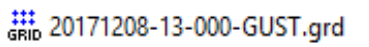 & 08/12/2017 22:36 & Surfer Grid & $1 \mathrm{~KB}$ \\
\hline 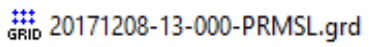 & 08/12/2017 22:36 & Surfer Grid & $1 \mathrm{~KB}$ \\
\hline 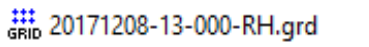 & 08/12/2017 22:36 & Surfer Grid & $1 \mathrm{~KB}$ \\
\hline$\underset{\text { GRID }}{\text { 㳖 20171208-13-000-TMP.grd }}$ & 08/12/2017 22:36 & Surfer Grid & $1 \mathrm{~KB}$ \\
\hline 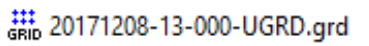 & 08/12/2017 22:36 & Surfer Grid & $1 \mathrm{~KB}$ \\
\hline 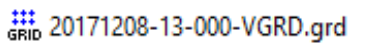 & 08/12/2017 22:36 & Surfer Grid & $1 \mathrm{~KB}$ \\
\hline 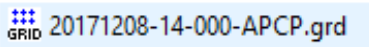 & 08/12/2017 22:36 & Surfer Grid & $1 \mathrm{~KB}$ \\
\hline 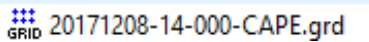 & $08 / 12 / 201722: 36$ & Surfer Grid & $1 \mathrm{~KB}$ \\
\hline
\end{tabular}

Hình 5. Phương thức lư trũ truòng yếu tố thòi tiết dạng lưới số liệu

Module này cho phép tự động xác định các thời điểm thu nhận số liệu mô hình từ website của NOAA, với tần xuất 4 lần/ngày vào các thời điểm $1,7,13$ và 19 giờ Hà Nội với thời gian trễ của mô hình từ 3.5 đến 4 giờ. Sau khi thu nhận, phần mềm sẽ giải mã tạo thành các tệp tin số liệu dạng lưới trên các mặt đẳng áp khác nhau, tệp tin có cấu trúc: yyyymmdd-hh-HHH-ParameterCode, trong đó dãy yyymmdd là ngày tháng năm, hh-HHH là khoảng thời gian, ParamenterCode tên tệp dữ liệu, ví dụ: Tmax.grd là tệp tin về nhiệt độ tối cao (Hình 5).

3.1.2. Xây dụng module kết nối co sở dũ liệu dư báo với trường thuộc tính GIS

Các yếu tố dự báo của mô hình được tính toán cho các ô lưới dữ liệu, từ ô lưới chuyển thành các giá trị dự báo cho các khu vực không gian nhất định. Để đưa được giá trị dự báo đến cấp xã của tỉnh Long An, việc chồng chập các lớp lưới từ dữ liệu số đã được chuyển đổi từ định dạng GRIB2 sản phẩm của GFS cần được nội suy cho phù hợp. Phương pháp thực hiện đối với các trường hợp như sau:

- Nếu có hơn một ô lưới nằm trong không gian của đơn vị hành chính, tiến hành tính toán giá trị yếu tố dự báo bằng phương pháp trung bình cộng các ô lưới;

- Nếu không có ô lưới nào nằm trong không gian đơn vị hành chính, tiến hành xác định tâm của khu vực hành chính, tính toán trung bình cộng của 4 ô lưới xung quanh tâm vừa xác định, hoặc nội suy khoảng cách để xác định giá trị điểm tâm khu vực 4 ô lưới trên (Hình 6). 


\section{BÀI BÁO KHOA HỌC}

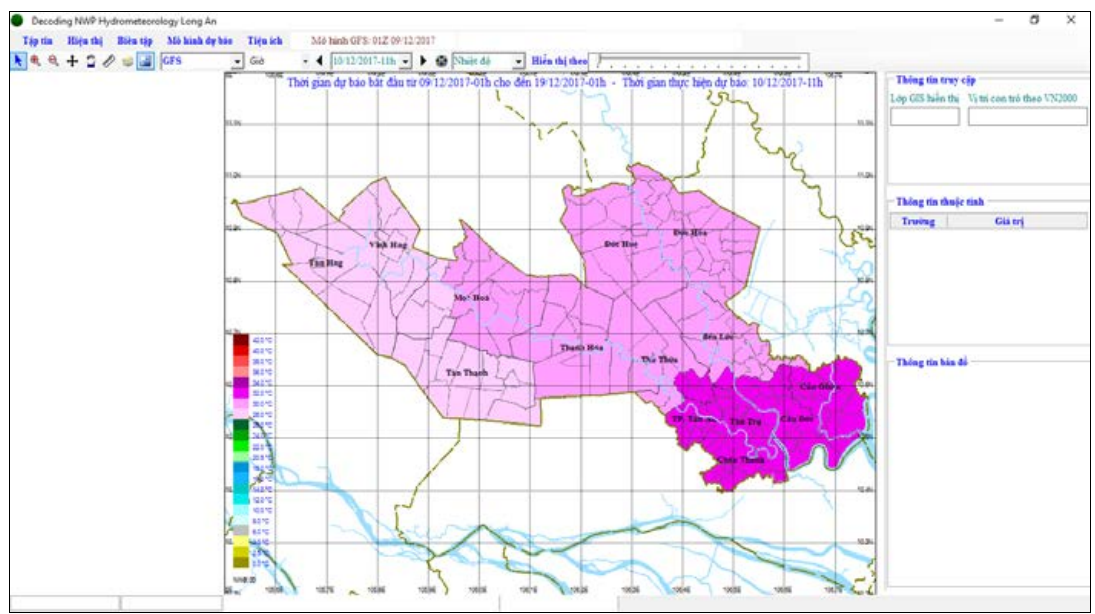

Hình 6. Phưong pháp xác định số ô luới trong một đơn vị hành chính

\subsubsection{Xây dựng module hiển thị và cung cấp} kết quả dụ báo

Để quản lý thông tin cung cấp cho các tổ chức, cá nhân theo quy định, module cung cấp kết quả dự báo được xây dựng để cung cấp sản phẩm dự báo cho cơ quan phòng chống thiên tai, các nhà quản lý, các đơn vị truyền thông và cho cộng đồng thông qua các phương thức gửi bản tin tự động qua email (Hình 7), cung cấp trên website có thể truy cập trên các thiết bị thông minh.

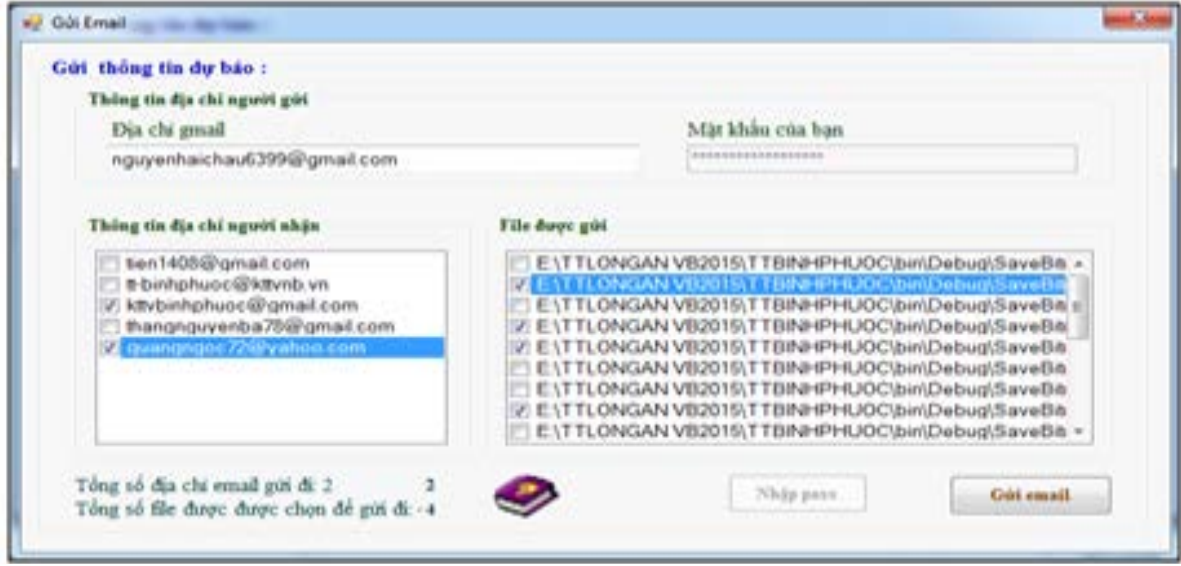

Hình 7. Gưi bản tin theo hình thức thu điện tư

Để cung cấp rộng rãi đến từng đối tượng trong cộng đồng, module hiển thị kết quả dự báo đã được tích hợp trên môi trường internet qua trang web "thoitietlongan.net”. Kết quả tính toán và hiển thị các giá trị dự báo thời tiết thời đoạn 10 ngày cho các đơn vị hành chính có thể được trích xuất dưới dạng file word giúp dự báo viên kết xuất các bản tin dự báo cho các huyện, xã tỉnh Long An, kết quả ở dạng biểu đồ và dạng bảng, thông tin tự động cập nhật trên website sau 3 giây (Hình 8).
Đối với dạng tin dự báo thể hiện bằng bản đồ GIS, hằng ngày kết quả dự báo được thể hiện trực quan trên bản đồ cho từng yếu tố khí tượng, người dùng có nhu cầu xem diễn biến dự báo thời tiết 10 ngày tiếp theo thực hiện nhấp chuột vào Next data hoặc xem dưới dạng video. Bản đồ dự báo trực quan cung có thể được trích xuất cho các vùng huyện của tỉnh Long An, bản đồ thời tiết cũng tự tự động cập nhật trên website sau 3 giây (Hình 9). 


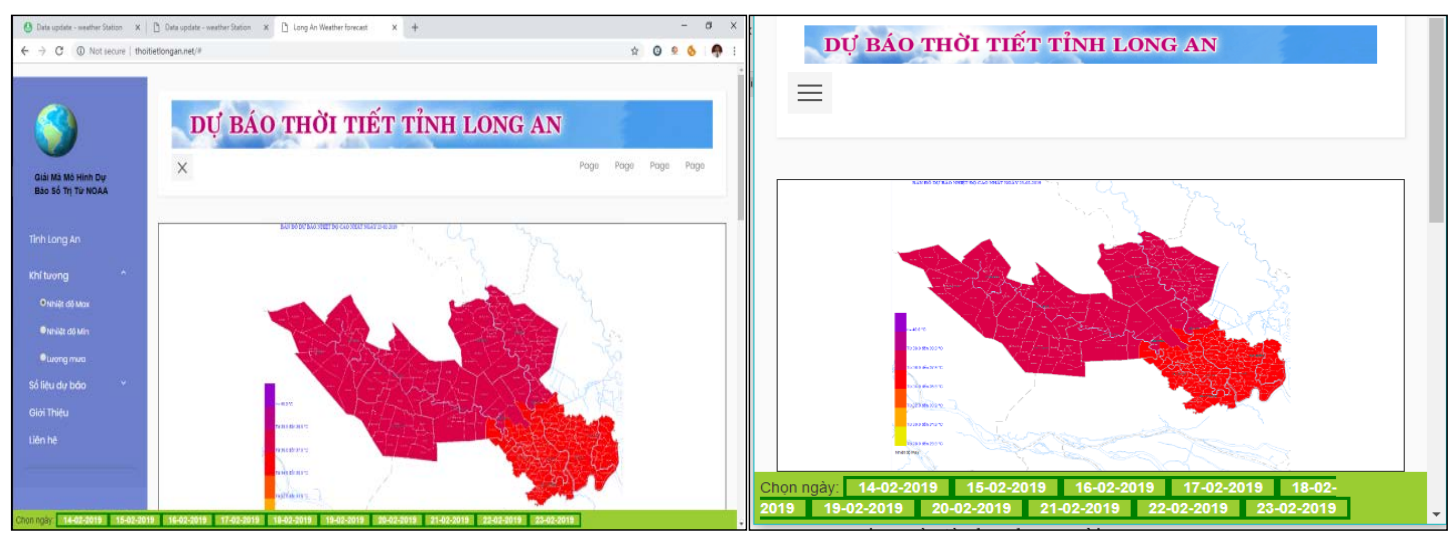

Hình 9. Kết quả dụ báo trên nền GIS hiển thị website truy cập tù máy tính và điện thoại di động

3.2. Tính hiệu quả của ứng dụng hệ thống thông tin địa lý trong dụ báo khí tượng thủy văn ở Long An

Việc xây dựng bộ công cụ giải mã số liệu dự báo từ mô hình dự báo số trị toàn cầu GFS của NOAA, kết hợp kinh nghiệm phân tích của dự báo viên Đài Khí tượng Thủy văn tỉnh Long An, hiển thị thông tin dự báo bằng bản đồ trực quan trên nền hệ thống thông tin địa lý GIS đã đem lại hiệu quả thiết thực, góp phần nâng cao độ tin cậy của bản tin dự báo, thuận tiện cho người sử dụng có thể dễ dàng tiếp cận thông tin dự báo một cách nhanh chóng. Những hiệu quả cụ thể bộ công cụ đã mang lại:

- Cung cấp thêm thông tin tham khảo từ kết quả dự báo của mô hình số trị GFS, kết hợp với số liệu quan trắc từ các trạm khí tượng thủy văn trên địa bàn tỉnh, kinh nghiệm phân tích của dự báo viên, đã góp phần nâng cao chất lượng của bản tin dự báo.

- Việc cung cấp bản tin dự báo cho cơ quan quản lý, phòng, chống thiên tai và cơ quan truyền thông trước kia đơn thuần là gửi qua thư điện tử email và tin nhắn SMS, qua bộ công cụ này người sử dụng bản tin dự báo có thể dễ dàng cập nhật thông tin chỉ bằng điện thoại di động thông minh.

- Hiển thị thông tin dự báo trên nền bản đồ GIS, giúp người dùng dễ hiểu, dễ tiếp cận thông tin, đem đến sự phong phú trong việc cung cấp thông tin dự báo.

- Úng dụng GIS trong cung cấp bản tin dự báo trực quan đến cấp huyện, xã có thể giúp tăng cường công tác quản lý ở các lĩnh vực khác như nông nghiệp, lâm nghiệp, thủy sản, giao thông...thông qua việc chồng chập các lớp bản đồ chuyên ngành với bản đồ dự báo khí tượng thủy văn được xây dựng từ bộ công cụ này.

\section{Kết luận}

Úng dụng công nghệ GIS trong quản lý các ngành, lĩnh vực kinh tế - xã hội đã và đang được thực hiện rất hiệu quả, đặc biệt các lĩnh vực có đối tượng liên quan đến không gian, thời gian như khí tượng thủy văn. Với những tính năng ưu việt của GIS, nhóm nghiên cứu đã tận dụng cơ sở dữ liệu GIS đã được tỉnh Long An đầu tư xây dựng trước đó để xây dựng bộ công cụ hiển thị kết quả dự báo khí tượng thủy văn từ việc giải mã thông tin dự báo của mô hình số trị GFS từ Cục Quản lý khí quyển và đại dương Hoa Kỳ NOAA. Bộ công cụ được hoàn thiện thông qua kết nối các mảng module với các chức năng riêng biệt gồm:

Module tự động cập nhật số liệu GRIB2 từ Sercurity FTP của NOAA; module kết nối và giải mã tập tin GRIB thành tệp tin GRID, số hóa dữ liệu và kết nối với thuộc tính của GIS; module hiển thị sản phẩm dự báo từ $24 \mathrm{~h}-48 \mathrm{~h}$, từ 2 ngày đến 10 ngày trên nền GIS.

Bộ công cụ đã hoàn thiện và chạy thử nghiệm thành công, cho phép người dùng truy vấn và hiện thị diễn biến các yếu tố khí tượng theo thời gian, trợ giúp người dùng đánh giá diễn biến thời tiết trong một thời khoảng nhất định, công cụ này có thể tự động cập nhật thông tin dự báo cho tỉnh Long An với các định dạng khác nhau, trực quan, dễ hiểu, chi tiết đến đơn vị hành chính cấp huyện, xã. 


\title{
Tài liệu tham khảo
}

1. Nguyễn Hải Sơn (2011), Úng dụng thông tin địa lý GIS dụ báo nguy co cháy rùng tỉnh Bình Phước. Đề tài nghiên cứu khoa học cấp tỉnh.

2. Đài Khí tượng Thủy văn tỉnh Quảng Nam, (2014), Úng dụng công nghệ GIS để xây dưng bản đồ chi huy phòng chống lũ lụt tỉnh Quảng Nam. Dự án do UBND tỉnh Quảng Nam đầu tư.

3. Rutledge, G.K., Alpert, J., Ebuisaki, W. (2006), A Climate and Weather Model Archive at the National Oceanic and Atmospheric Administration.

4. Ebisuzaki, W. (2013), Introduction to GRIB2 using GFS forecasts, ftp.cpc.ncep.noaa.gov.

\section{STUDY ON APPLICATION OF GEOGRAPHICAL INFORMATION SYSTEM (GIS) TO BUILD A HYDRO-METEOROLOGY FORECAST INFORMATION DISPLAYING SYSTEM FOR LONG AN PROVINCE Nguyen Quang Ngoc ${ }^{1}$, Nguyen Hai Son ${ }^{2}$ \\ ${ }^{1}$ Long An Hydorlogical Meteorological Center \\ ${ }^{2}$ Binh Phuoc Hydorlogical Meteorological Center}

\begin{abstract}
Currently, the tendency of visualizing and mapping information is being applied very effectively in many sectors and fields, especially in Hydro-meteorology. Software for processing and managing geographic information systems (GIS) is developed signiciantly and increasingly, allowing to connect, overlap many layers, automatically and easily display information on the mapbase. In order to take advantage of available GIS information resources, we have built a tool to provide weather forecast information in Long An province by showing the forecast results based on GIS maps. This article presents the technical content for building data decoding modules from predictive data of GFS model (NOAA), the forecasting data connection module with the GIS and the project of displaying prediction results. The result has created a toolkit that automatically provides forecast reports according to visual maps to district and commune levels for Long An province, helping users to exploit the products on the internet.
\end{abstract}

Keywords: Application of GIS weather forecast for Long An province, Weather forecast of Long An commune 